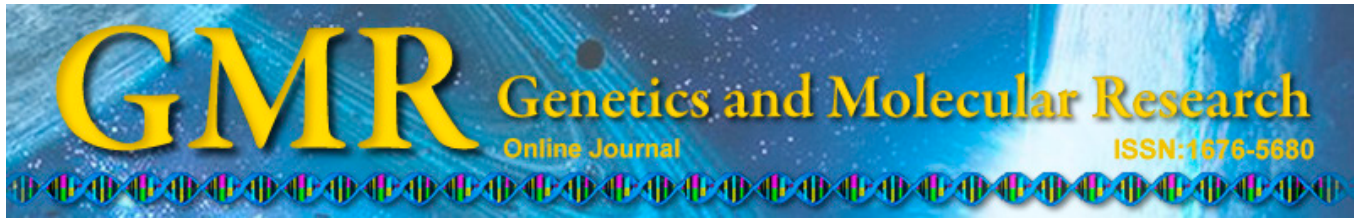

\title{
Study of nucleolar behavior during spermatogenesis in Martarega brasiliensis (Heteroptera, Notonectidae)
}

L.L.V. Pereira ${ }^{1}$, K.C.C. Alevi ${ }^{2}$, F.F.F. Moreira ${ }^{3}$, J.F. Barbosa ${ }^{4}$, E.R. Silistino-Souza ${ }^{1}$, F.C. Silva Júnior ${ }^{1}$, T.S. Souza-Firmino ${ }^{1}$, C.A. Banho ${ }^{1}$ and M.M. Itoyama ${ }^{1}$

${ }^{1}$ Laboratório de Citogenética e Molecular de Insetos, Departamento de Biologia, Instituto de Biociências, Letras e Ciências Exatas, Universidade Estadual Paulista "Júlio de Mesquita Filho",

São José do Rio Preto, SP, Brasil

${ }^{2}$ Laboratório de Biologia Celular, Departamento de Biologia,

Instituto de Biociências, Letras e Ciências Exatas,

Universidade Estadual Paulista "Júlio de Mesquita Filho",

São José do Rio Preto, SP, Brasil

${ }^{3}$ Laboratório Nacional e Internacional de Referência em Taxonomia de Triatomíneos, Instituto Oswaldo Cruz, FIOCRUZ, Rio de Janeiro, RJ, Brasil

${ }^{4}$ Laboratório de Entomologia, Departamento de Zoologia, Universidade Federal do Rio de Janeiro, Rio de Janeiro, RJ, Brasil

Corresponding author: K.C.C. Alevi

E-mail: kaiochaboli@hotmail.com

Genet. Mol. Res. 14 (3): 8988-8994 (2015)

Received August 15, 2014

Accepted March 26, 2015

Published August 7, 2015

DOI http://dx.doi.org/10.4238/2015.August.7.7

ABSTRACT. Few cytogenetic studies have been undertaken using aquatic heteropterans and the nucleolar behavior of these insects has been described in only four species, Limnogonus aduncus, Brachymetra albinerva, Halobatopsis platensis, and Cylindrostethus palmaris. The nucleolus is a cellular structure related to biosynthetic 
activity and it exhibits a peculiar behavior in the heteropterans of the Triatominae subfamily; it persists during all stages of meiosis. Thus, this study aims to analyze spermatogenesis in Martarega brasiliensis, with an emphasis on nucleolar behavior. Twenty $M$. brasiliensis adult males were used and collected from the Municipal reservoir in the city of São José do Rio Preto, São Paulo, Brazil. The species were fixed in methanol:acetic acid (3:1), then dissected, and the testicles were extracted, torn apart, and impregnated with silver ions. During prophase, the nuclei of $M$. brasiliensis were composed of the nucleolus and nucleolar corpuscles, which varied in number from one to four, emphasizing that this insect has great synthetic activity during meiosis. The analysis of cells in metaphase I showed that $M$. brasiliensis presents a nucleolar organizing region in at least one autosome. Furthermore, the phenomenon of nucleolar persistence was not observed. All spermatids presented nucleolar markings that varied in number and position according to the stage of elongation. Moreover, it was also possible to highlight the presence of a vesicle in spermatids. Thus, this paper describes the nucleolar behavior of $M$. brasiliensis and highlights important characteristics during spermatogenesis, thus, increasing the knowledge about the biology of these aquatic heteropterans.

Key words: Aquatic Heteroptera; Spermatogenesis; Meiosis

\section{INTRODUCTION}

The order Hemiptera is composed of three suborders: Auchenorrhyncha, Heteroptera, and Sternorrhyncha (Cryan and Urban, 2012). The suborder Heteroptera has seven infraorders with approximately 80 families, the majority of which occur on all continents (except Antarctica) and some islands.

The heteropterans exhibit great variation in their occupancy of habitats and they can be found in terrestrial, aquatic, or semi-aquatic environments, and they also exhibit great variation in their method of feeding, being phytophagous, hematophagous, or predators (Gullan and Cranston, 2007). Aquatic and semi-aquatic heteropterans are widely distributed and have an extraordinary ability to inhabit a variety of ecosystems, being found in freshwater and marine habitats, at a variety of altitudes ranging from 0 to $4700 \mathrm{~m}$ (Melo, 2009). Thus, these insects have great economic and epidemiological importance as agricultural pests and vectors of Chagas disease, respectively. Moreover, these insects are important models for cellular studies because they present some peculiarities in their holocentric chromosomes and undergo inverted meiosis in their sex chromosomes (Ueshima, 1979).

There have been few cytogenetic studies of aquatic heteropterans (Castanhole et al., 2008, 2010). Of these insects, the nucleolar behavior is only known for the species Limnogonus aduncus, Brachymetra albinerva, Halobatopsis platensis, and Cylindrostethus palmaris (Castanhole et al., 2008, 2010). The nucleolus is a cellular structure related to biosynthetic activity, therefore, the size and number of nucleoli and nucleolar corpuscles 
present in the nucleus depends on the functional characteristics of the cells, which may then reflect on metabolic and functional differences (Tavares and Azevedo-Oliveira, 1997; Souza et al., 2007a,b; Alevi et al., 2013).

During spermatogenesis in eukaryotes, the nucleolus dissociates at the end of prophase and reorganizes during telophase (González-Garcia et al., 1995). However, in the heteropterans of the Triatominae subfamily, reports exist of the persistence of the nucleolus or nucleolar corpuscles during the whole process of meiosis, a phenomenon termed nucleolar persistence (Tartarotti and Azeredo-Oliveira, 1999; Alevi et al., 2013, 2014a). Thus, this study aims to analyze spermatogenesis in Martarega brasiliensis, with an emphasis on nucleolar behavior.

\section{MATERIAL AND METHODS}

A total of 20 adult males of $M$. brasiliensis were collected from the Municipal reservoir in the city of São José do Rio Preto, São Paulo, Brazil, with the aid of nets, and transported in pots to Laboratório de Citogenética e Molecular de Insetos of UNESP/IBILCE. The species were fixed in methanol:acetic acid (3:1), then dissected, and the testicles were extracted, torn apart, and impregnated with silver ions, as described in the protocol by Howell and Black (1980). The best images were captured using a ZEISS Axio Scope A1 microscope and analyzed using the AXIO VISION LE version 4.8 software.

\section{RESULTS}

Nucleolar behavior was observed during meiosis using the cytochemical technique of impregnation of silver ions (Figures 1a-f and 2a-h). During prophase I, beyond the nucleolus with a rounded morphology (Figure 1a-e), between one and four nucleolar corpuscles were observed in the cell nuclei (Figure 1b-e). Cells in metaphase I presented markings of the nucleolar organizer regions (NOR) in the telomeric region of one of the autosomes (Figure 1f). During anaphase I, various corpuscles with different sizes and shapes were observed within the cells (Figure 2a), along with late migration of the sex chromosome (Figure 2a). Cells in telophase I presented up to two marks (Figure 2b). Regarding spermiogenesis, early stage spermatids were rounded and presented nucleolar markings only in the region where the tail was beginning to form (Figure 2c). During the elongation of spermatids, the nucleolus and nucleolar corpuscles were observed (Figure 2d). Furthermore, the presence of a large vesicle and rounding at the anterior region of the head of early spermatids was observed (Figure 2c-e). Rod-shaped spermatids presented two corpuscles (Figure 2f), discrete impregnations in the head (Figure 2f), and a tag dividing the spermatid longitudinally (Figure 2f). In the final phase, elongated rod-shaped spermatids with persistent nucleolar corpuscles were observed (Figure $2 \mathrm{~g}$ ) and elongated spermatids with markings in the anterior region of the head were recorded (Figure $2 \mathrm{~h}$ ).

\section{DISCUSSION}

Species of the Martarega genus, belonging to the family Notonectidae, are popularly known as backswimmers because they have rear legs adapted for swimming (Ueshima, 1979). 


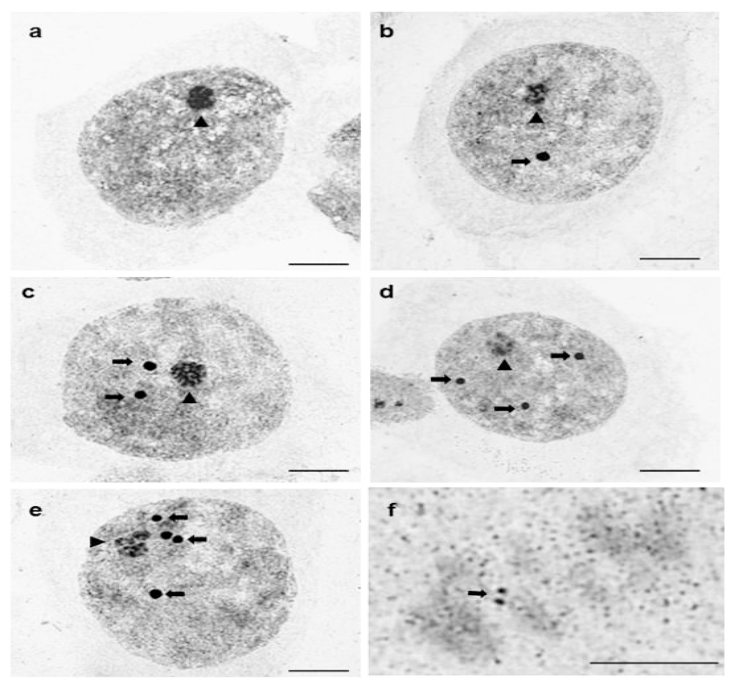

Figure 1. Cells of the seminiferous tubules of Martarega brasiliensis, impregnated with silver ions. a.-e. Prophase I. Note the presence of the rounded nucleolus (arrowhead) and nucleolar corpuscles (arrow) that varied in number: a. Absence of nucleolar corpuscles; b. one nucleolar corpuscle; c. two nucleolar corpuscles; d. three nucleolar corpuscles, and e. four nucleolar corpuscles; f. metaphase I. Note the presence of the nucleolar organizer regions (arrow) in the telomeric region of one autosome. Scale bar $=10 \mu \mathrm{m}$.

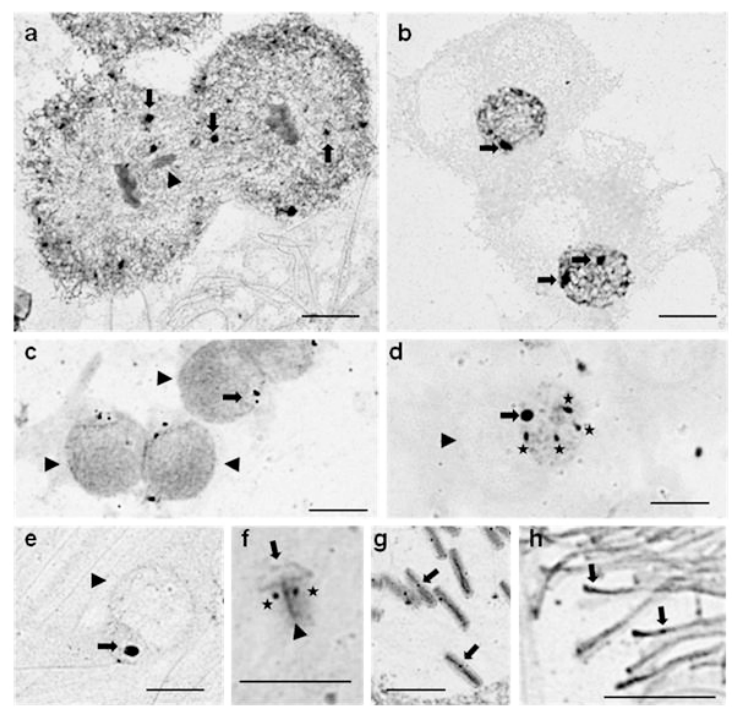

Figure 2. Cells of the seminiferous tubules of Martarega brasiliensis, impregnated with silver ions. a. Anaphase I with various corpuscles of different sizes and shapes (arrows) and late migration of the sex chromosome (arrowhead). b. Telophase with up to two marks (arrows). c. Early spermatids with marking in the posterior region (arrows) and vesicles in the anterior region of the head (arrowheads). d. Initial round spermatid with a nucleolus (arrow) and four nucleolar corpuscles (asterisks). Note the presence of large, rounded vesicles (arrowhead). e. Elongating spermatid with marking in the posterior region (arrow) and vesicles in the anterior head (arrowhead). f. Rod-shaped spermatid presenting two corpuscles (asterisks), discrete impregnations in the head (arrow), and a tag dividing the spermatid longitudinally (arrowhead). g. Elongated rodshaped spermatids with persistence of positive silver corpuscles (arrows). h. Elongated spermatids with marking in the head region (arrows). Scale bar $=10 \mu \mathrm{m}$. 
During meiosis of M. brasiliensis, we observed nucleologenesis, with nuclei in prophase I composed of the nucleolus and nucleolar corpuscles that varied in number from one to four. This variation in the number of nucleolar corpuscles is related to the synthetic activity of the cells (Tavares and Azeredo-Oliveira, 1997; Bressa et al., 2002). Alevi et al. (2013) analyzed the nucleolar markings of two species of triatomine bugs (Triatoma lenti and Triatoma melanocephala) and found that the species with the highest number of markings showed the greatest synthetic activity. Thus, the results presented here indicate that $M$. brasiliensis has great synthetic activity during meiosis. However, we emphasize that this variation in the number of nucleolar corpuscles may be related to the transcriptional needs of the cell during cell division.

Although technical impregnation by silver ions is applied extensively to studies of NORs (Howell and Black, 1980), the holocentric nature of the chromosomes of hemipterans makes it difficult to mark the NORs. Using the technique of silver ions to mark the NORs that were active in the previous interphase, thus analyzing the cells in metaphase I, we observed that $M$. brasiliensis presents NOR in at least one autosome. This feature was also observed in the chromosomes of L. aduncus (Castanhole et al., 2008).

The phenomenon of nucleolar persistence is characterized by the presence of the nucleolus or nucleolar corpuscles during metaphase (Alevi et al., 2014a). M. brasiliensis showed no nucleolar persistence because the presence of a NOR was only observed during metaphase I. This same feature was also observed for L. aduncus (Castanhole et al., 2008). The presence of nucleolar corpuscles during the phases of meiosis have been characterized in other insects of the order Hemiptera: Carlisis wahlbergi (Fossey and Liebenberg, 1995) Acanthocoris sordidus, and Coptosoma punctissimum (Yoshida, 1950), and 21 species of the Triatominae subfamily (Alevi et al., 2014a). Alevi et al. (2014a) proposed that nucleolar persistence may be a synapomorphy of the subfamily Triatominae.

During spermiogenesis, all spermatids presented nucleolar marks that varied in number and location in accordance with the phase of elongation. The presence of nucleolar corpuscles during all stages of spermatogenesis has already been observed in aquatic Heteroptera (Castanhole et al., 2008). In B. albinerva, H. platensis, and C. palmaris, cells with one or more corpuscles were observed to turn around the perichromosomal sheath during disorganization. The round spermatids presented two close corpuscles and during stretching, one corpuscle remained in the head and the other migrated to the initial part of the tail. At the end of the spermiogenesis process, these markings were not visualized (Castanhole et al., 2010).

Although nucleolar marks were observed in spermatids of $M$. brasiliensis, recently Alevi et al. (2014b) suggested that the cells of hemipterans do not have transcriptional activity during spermiogenesis. The authors highlight the relationship of nucleolar markings with regions of constitutive heterochromatin and suggest that the nucleolus is inactivated by epigenetic factors and that the organelle chromatoid body supplies all transcriptional activity during cell differentiation. Thus, we emphasize the importance of further studies using specific epigenetic markers to investigate whether the nucleolar material observed in M. brasiliensis has transcriptional activity.

A peculiarity observed during spermiogenesis of M. brasiliensis was the presence of a vesicle in the spermatids, which has not been observed in the terrestrial (Souza et al., 2007a,b, 2008, 2009) and aquatic species (Castanhole et al., 2008, 2010) studied. Thus, we emphasize that ultrastructural studies are required to describe this structure in more detail in order to clarify its relationship with the formation of sperm. 
In conclusion, this paper describes the nucleolar behavior of M. brasiliensis and highlights important characteristics observed during spermatogenesis, increasing the knowledge about the biology of these aquatic heteropterans.

\section{Conflicts of interest}

The authors declare no conflict of interest.

\section{ACKNOWLEDGMENTS}

Research supported by Fundação de Amparo à Pesquisa do Estado de São Paulo (FAPESP), Fundação de Desenvolvimento da UNESP (FUNDUNESP), Fundação de Apoio à Pesquisa e Extensão de São José do Rio Preto (FAPERP), and Conselho Nacional de Desenvolvimento Científico e Tecnológico (CNPq).

\section{REFERENCES}

Alevi KCC, Mendonça PP, Pereira NP, Rosa JA, et al. (2013). Análise das possíveis Regiões Organizadoras Nucleolares e da atividade nucleolar em Triatoma melanocephala e T. lenti, importantes vetores da doença de Chagas. Rev. Cienc. Farm. Básica Apl. 34: 417-421.

Alevi KCC, da Costa Castro NF, Lima AC, Ravazi A, et al. (2014a). Nucleolar persistence during spermatogenesis of the genus Rhodnius (Hemiptera, Triatominae). Cell Biol. Int. 38: 977-980.

Alevi KCC, Mendonça PP, Pereira NP, Rosa JA, et al. (2014b). Is there post-meiotic transcriptional activity during hemipteran spermiogenesis? Invertebr. Reprod. Dev. 58: 193-198.

Bressa MJ, Fumagalli E, Ituarte S, Frassa MV, et al. (2002). Meiotic studies in Dysdercus Guérin Méneville, 1831 (Heteroptera: Pyrrhocoridae). II. Evidence on variations of the diffuse stage between wild and laboratory-inbred populations of Dysdercus chaquensis Freiberg, 1948. Hereditas 137: 125-131.

Castanhole MMU, Pereira LLV, Bicudo HEMC, Costa LAA, et al. (2008). Heteropicnotic chromatin and nucleolar activity in meiosis and spermiogenesis of Limnogonus aduncus (Heteroptera, Gerridae): a stained nucleolar organizing region that can serve as a model for studying chromosome behavior. Genet. Mol. Res. 7: 1398-1407.

Castanhole MMU, Pereira LLV, Souza HV and Itoyama MM (2010). Spermatogenesis and karyotypes of three species of water striders (Gerridae, Heteroptera). Genet. Mol. Res. 9: 1343-1356.

Cryan JR and Urban JM (2012). Higher-level phylogeny of the insect order Hemiptera: is Auchenorrhyncha really paraphyletic? Syst. Entomol. 37: 7-21.

Fossey A and Liebenberg H (1995). Meiosis and nucleolar structures in the stink bug Carlisis wahlbergi Stal (Coreidae: Heteroptera). Cytobios 81: 7-15.

González-Garcia JM, Rufas JS, Antonio C and Suja JA (1995). Nucleolar cycle and localization of NORs in early embryos of Parascaris univalens. Chromosoma 104: 287-297.

Gullan PJ and Cranston PS (2007). Os insetos: um resumo de entomologia. 3rd edn. Roca, São Paulo.

Howell WM and Black DA (1980). Controlled silver-staining of nucleolus organizer regions with a protective colloidal developer: a 1-step method. Experientia 36: 1014-1015.

Melo MC (2009). Biodiversidad de Heteroptera (Hemiptera) acuáticas y semiacuáticas de la Patagonia argentina. Rev. Soc. Entomol. Argent. 68: 177-185.

Souza HV, Arakaki RLM, Dias LN, Murakami AS, et al. (2007a). Cytogenetical aspects of testicular cells in economically important species of Coreidae family. Cytologia 72: 49-56.

Souza HV, Bicudo HEMC and Itoyama MM (2007b). Study of chromosomal and nucleolar aspects in testes of Nysius californicus (Heteroptera: Lygaeidae). Genet. Mol. Res. 6: 33-40.

Souza HV, Castanhole MMU, Bicudo HEMC, Costa LAA, et al. (2008). Morphological patterns of the heteropycnotic chromatin and nucleolar material in meiosis and spermiogenesis of some Pentatomidae (Heteroptera). Genet. Mol. Biol. 31: 686-691.

Souza HV, Souza FB, Maruyama SRC, Castanhole MMU, et al. (2009). Meiosis, spermatogenesis and nucleolar behavior in the seminiferous tubules of Alydidae, Coreidae and Rhopalidae (Heteroptera) species. Genet. Mol. Res. 8: 1383-1396. 
Tartarotti E and Azeredo-Oliveira MTV (1999). Patterns of nucleolar activity during spermatogenesis of two triatomines, Panstrongylus megistus and P. herteri. Caryologia 52: 177-184.

Tavares MG and Azeredo-Oliveira MTV (1997). Pattern of nucleolar activity during spermiogenesis in triatomines (Heteroptera, Reduviidae) as analyzed by silver-staining. Cytobios 89: 93-103.

Ueshima N (1979). Hemiptera II: Heteroptera. In: Animal cytogenetics. Vol. 3. Insecta, 6. Gebruder Borntraeger, Berlin, 1-117.

Yoshida TH (1950). Remarkable behavior of the nucleolus in meiosis of Acanthocoris sordidus Thumb. (Heteroptera) (in Japanese). La Kromosomo 7: 273-282. 